\title{
¿Existe la Publicidad Intercultural?
}

\author{
Does intercultural \\ advertising exist?
}

\author{
Francesca Senesi (Italia) \\ francesca.senesi@teletu.it \\ Especialista en Filosofía \\ Universidad Sergio Arboleda
}

\section{David Riccivlli-Duarte (Colombia)}

\section{Resumen \\ Este artículo de reflexión problematiza sobre la naturaleza de la publicidad intercultural desde el punto de vista de la sociedad contemporánea y su papel en la construcción de narrativas sobre la diversidad. A través de una revisión de la literatura disponible sobre el tema y el análisis de piezas publicitarias, se encuentra que este tipo específico de publicidad es una herramienta que permite construir una sociedad en la}

\author{
dricciul@poligran.edu.co \\ Comunicador Social-Periodista \\ Máster en Diseño de Videojuegos \\ Institución Universitaria Politécnico Grancolombiano
}

mintucion Universitain Politecrico Grancolombiano

\begin{tabular}{|c|c|c|}
\hline RECIBIDO: & 17 DE DICIEMBRE DE 2015 & Para CItAR ESTE artículo / to CITE thIS ARTICLE \\
\hline EVALUADO: & 7 DE JULOO DE 2016 & Senesi, F. \& Ricciulli, D.(2017). ¿Existe la Publicidad \\
\hline ACEPTADO: & 12 DE SEPTIEMBRE DE 2016 & Intercultural?, Poliantea, 13(24), pp.-167-196 \\
\hline
\end{tabular}

\begin{abstract}
Summary
This reflective article questions the nature of intercultural advertising from a contemporary society point of view, and its role in diversity narratives construction. Through an available literature review and advertising pieces analysis, it is found that this specific type of advertising is a tool that allows to build a society where interculturality is perceived as a positive and desirable value, in opposition to "cultural homologation" processes,
\end{abstract}


que la interculturalidad se percibe como un valor positivo y deseable, en contraposición a los procesos de "homologación cultural" que se entienden como herramientas para invisibilizar la diversidad.

Palabras clave: publicidad, interculturalidad, publicidad intercultural, sociedad incluyente y pacifica. understood as tools to make diversity invisible.

Keywords: advertising, interculturality, intercultural advertising, inclusive and peaceful society. 
La hospitalidad "es recibir al otro en una medida desmesurada, más allá de la capacidad del yo"

DERRIDA, J.

Adiós a Emmanuel Lévinas

\section{Introducción}

Este texto se adhiere a una perspectiva filosófica sobre la Publicidad, al impacto que tiene sobre la sociedad y su capacidad de generar una sociedad progresivamente más incluyente y participativa. En este sentido, los principios de la Publicidad Social, que busca la integración de los principios del marketing para el beneficio colectivo, son el punto de partida de esta aproximación.

El objetivo de este documento es llamar la atención de publicistas, expertos y de la población comprometida con el cambio social, para que se acerquen a los principios de la Publicidad Social para el desarrollo de una sociedad intercultural incluyente, equitativa y pacífica. Se aclara que no tiene pretensiones de ser una investigación exhaustiva que proponga una solución o que cierre el diálogo, sino más bien un aporte para visibilizar esta problemática en el quehacer publicitario.

Los aportes de la Publicidad Social para el desarrollo de una sociedad intercultural son especialmente valiosos en el contexto global actual, en el que el choque entre culturas es cada vez más frecuente y en donde los efectos negativos de estos encuentros desestabilizan gobiernos y dividen naciones. La crisis de refugiados de 2016, el movimiento Black Lives Matter, los ataques terroristas de extremistas religiosos y las crisis sociales y étnicas potenciadas por la globalización dan cuenta de la necesidad de promover un discurso de unidad e integración a través de la Publicidad.

Por eso, es precisamente desde esos procesos de interculturalización, de apropiación y de choques entre culturas, desde donde se debe 


\section{- ¿Existe la Publicidad Intercultural? - Francesca Senesi, David Ricciulli-Duarte}

parar este análisis para indagar sobre esos momentos específicos en los que la publicidad reconoce a la interculturalidad y los procesos semióticos que ocurren allí.

\section{Método}

Una aproximación inicial fue realizada mediante el método de Revisión Sistemática de Literatura (RSL) de Kitchenham (2004), en el que se utilizó la siguiente ecuación de búsqueda:

\section{(ALL(ADVERTISING) AND ALL3}

La selección de esta combinación de términos se hizo teniendo en cuenta la posibilidad de hallar reflexiones académicas en las que se desarrollaran las problemáticas asociadas con la representación de la interculturalidad en el campo de la publicidad.

La revisión inicial arroja solamente cuatro documentos que van desde 1999 a 2016. Ante la ausencia de resultados concluyentes o evidencia de estudios previos específicos, se adopta una aproximación descriptiva y una búsqueda bibliográfica de "interculturalidad" y "Publicidad" que arroja un acervo de aproximaciones sobre "Comunicación
Intercultural", que pese a no presentar una perspectiva específica sobre la publicidad, sí permite recoger apreciaciones valiosas que se describirán a continuación:

(ALL(COMMUNICATION) AND

ALL(INTERCULTURALISM))

AND ( LIMIT-TO ( DOCTYPE," ar “) ) AND ( LIMIT-TO

( SUBJAREA,"SOCI" ) OR LIMIT-

TO ( SUBJAREA,"ARTS") OR

LIMIT-TO ( SUBJAREA,"BUSI" ) )

\section{Publicidad como agente homogenizador}

$\mathrm{Al}$ respecto, Rey (2006) plantea un debate sobre los efectos de la publicidad como agente homogenizador de las culturas desde el que se sitúan dos miradas, la de los Apocalípticos, para quienes "la cultura occidental homologa y uniforma el mundo al imponer su modelo"(p. 202) y la de los integrados que "contemplan la existencia de un sujeto con voluntad al que hay que convencer y quien integra en su quehacer diario el producto y su simbología" (p. 203).

Esta perspectiva concluye que la publicidad genera un efecto homogenizador en voz del capitalismo internacional, pero señala que este 
efecto es parcial, no absoluto y que se produce más bien, un proceso de "hibridación" en el que naturalmente ocurren relaciones asimétricas en el que una cultura "invadida" consume de manera crítica los dictados de la cultura invasora. En este proceso la cultura dominante se integra en la cotidinidad de la cultura dominada, en una especie de hibridación.

En la misma línea de Rey, se ubica Enrique Vergara (2003) que en "Los usos de la cultura en la creatividad publicitaria en Chile" evidencia la estrecha relación entre publicidad y cultura, reafirmando al mismo tiempo el carácter hibrido de los fenómenos culturales :

“(..) se hace necesario para la publicidad reconocer la importancia de la globalización en cuanto fenómeno socioeconómico y al mismo tiempo multicultural. Esto nos exige dejar de ver el mundo de forma única y etnocéntrica, y reconocer nuevas formas culturales en que se combina lo global con lo local. La globalización cultural en cuanto fenómeno dinámico, multidimensional y asimétrico nos permite superar las oposiciones global-local y homogenización-diversidad (pág.15).

\section{La publicidad como agente para la inclusión social}

Una segunda cuestión, relacionada con el papel de la publicidad como agente de inclusión, aparece en la revisión de literatura. Esta reflexión está más orientada a resolver la pregunta ¿Es la publicidad capaz de desempeñar un papel incluyente para las culturas minoritarias, específicamente para los inmigrantes que llegan de otro país? Es esa la pregunta que está a la base del artículo "Interculturalidad y Publicidad”, coordinado por Martínez-Corcuera (2005).

$\mathrm{El}$ autor afirma que "cuantitativamente, la representación de personajes de minorías en publicidad es muy limitado, prácticamente inexistente. Es la imagen de minorías invisibles o la aniquilación simbólica de su existencia" (pág. 10). En esta interacción, el autor entiende el papel de los medios y de la publicidad como "el proceso de conformación y condicionamiento de la realidad percibida por nuestra sociedad" (pág. 11) dando cuenta de una concepción esterotipada e idealizada sobre las minorías, que en la publicidad termina actuando de forma discriminatoria.

Resulta claro entonces que "los profesionales de la publicidad han 
de tener conciencia de su responsabilidad social en el fomento de valores que huyan de los prejuicios sociales y en el reconocimiento de la pertenencia y la participación social, cultural, política y económica de la diversidad de grupos étnicos y/o culturales"(pág. 11).

Otro texto que se ocupa de la misma inquietud para la inclusión social de la publicidad es " $\mathrm{Pu}$ blicidad e inmigración. Cómo los inmigrantes latinos perciben y reaccionan ante la publicidad" por Álvarez-Ruiz, A., Carcelén-García, S., López-Vázquez, B., Sebastián-Morillas A. \& Villagra-García, N.

Este texto atribuye una gran responsabilidad a la publicidad; afirma: "la integración no se consigue tanto por la publicidad como por la adquisición de derechos políticos y sociales (proceso lento) y por el consumo (proceso rápido). Sin embargo hay que señalar que, al igual que el resto de mensajes de los medios de comunicación, la publicidad puede contribuir en la construcción de un determinado discurso social positivo, mostrando y reforzando modelos de comportamiento integradores" (pág. 72).

Los sujetos de este estudio (los inmigrantes latinos) "en general, están de acuerdo con el papel que representan los latinos en la publicidad española, pero proyectan elementos aspiracionales y afirman desear verse reflejados en papeles de más importancia: abogados, médicos... Aunque, por otra parte, son bastante susceptibles a los estereotipos y creen que los anuncios de productos de élite deben ser anunciados por personajes que transmitan estatus" (pág. 74).

Como evidencia este estudio, desde el punto de vista del imaginario publicitario, la idea de una sociedad equitativa e inclusiva es todavía muy lejana, pues los migrantes son víctimas y artífices de prejuicios discriminatorios.

Otra pregunta que debe abordarse y se debe resolver es $>i$ La publicidad es universal o depende de las culturas de sus consumidores? A esta inquietud se dirige el trabajo "Valores interculturales en la comunicación publicitaria internacional: un análisis cualitativo basado en corpus, Identidades culturales y publicidad". La investigación aclara címo la publicidad se adapta a las culturas locales, tomando cm ejemplo representativo la compañía IKEA.

De hecho, "en el caso concreto de IKEA, llama la atención que, 
a pesar de que sus tiendas parecen idénticas por todas partes, cualquiera sea el país, la multinacional hace un esfuerzo marcado por tener en cuenta las expresiones lingüísticas propias de la cultura local a la que se dirige"(pág. 534).

Confirma esta idea Cepa-Giralt que en su "Globalización y diferencias culturales en publicidad" explica cómo "el presente trabajo nace con la intención de demostrar que, a pesar de la influencia de la globalización en la sociedad actual, siguen existiendo diferencias culturales entre los distintos países y estas diferencias las podemos observar en la publicidad. Los consumidores no son iguales en los distintos países y por ello, para que la comunicación sea más efectiva, los mensajes de los anuncios se deben adaptar al contexto social y cultural en el que se van a emitir" (pág. 10).

El ejemplo más indicativo que presenta la autora concierne la campaña que la empresa Samsung desarrolló en alianza con la Asociación contra el cáncer de mama en Francia y España. No obstante estos dos Países sean fronterizos y similares, la publicidad propuesta tiene un enfoque específico en cada realidad cultural:
"La versión española del anuncio es menos concreta pero además utiliza un lenguaje más poético con metáforas como el corazón evocando la solidaridad humana y agradeciendo el gesto de apoyo de los que ya han participado en la promoción" (pág. 14).

Una postura diferente aparece en el artículo "Globalización y publicidad: El lenguaje universal de los perfumes" de Montez-Fenández (2006), donde se afirma que

\begin{abstract}
"La publicidad convierte las marcas globales, conocidas en todo el mundo, en iconos del estilo de vida moderno, cosmopolita e individualizado. Mediante campañas publicitarias internacionales, se transmiten los nuevos valores globales a través de los distintos medios de comunicación impresos y audiovisuales. Los anuncios publicitarios de dichas marcas aparecen en los cinco continentes propagando el mismo mensaje publicitario. En cuanto al diseño general, los anuncios poseen la misma imagen, únicamente el texto ha sido adaptado a las culturas de recepción, en un ejercicio de localización, tal y como hoy en día se denomina el proceso de adaptación de una lengua y cultura concretas". (pág. 1-2).
\end{abstract}

El debate sobre la existencia de la publicidad intercultural puede, entonces, sintetizarse en dos tesis principales: 


\section{- ¿Existe la Publicidad Intercultural? - Francesca Senesi, David Ricciulli-Duarte}

1. La publicidad es universal, o sea, habla en el mismo lenguaje para todos los consumidores, con la consecuencia que homogeniza a las culturas, eliminando las diferencias específicas. Obviamente, en este primer caso, no puede existir una publicidad intercultural.

2. La publicidad se localiza, "se amolda" a los distintos contextos culturales. Claramente, en este segundo caso, puede hablarse del carácter intercultural de la publicidad.

Pero, ¿basta le basta a la publicidad realizar un ejercicio de localización para considerar sus contenidos interculturales?

La respuesta que se formula es que, si se considera a la publicidad intercultural como ela acción de vender el mismo producto a distintas culturas, la respuesta sería "sí", pero, si consideramos la publicidad intercultural como un factor incluyente relacionado con la publicidad social, la respuesta es que no.

Podemos concluir, por lo tanto, que, si buscamos una publicidad intercultural incluyente, tendremos que lograr una inclusión bilateral mediante la cual, no solo las minorías se transformen por cuenta de una cultura dominante, si no también que la mayoritaria sea fecundada por medio de las dominadas.

Es importante analizar la naturaleza de esta dinámica porque en el caso de una inclusión uniliateral, estaríamos hablando de ïntegración, proceso que deriva en muchos casos, en una desintegración de las alteridades para conformarse a una totalidad. Pero ¿es posible generar una interculturalidad simétrica en los medios masivos? Pese a que este fenómeno es común en la comunicación interpersonal, el reto que desafiaría a la publicidad intercultural como publicidad social.

Para desarrollar esta hipótesis, es necesario tener en cuenta los siguientes conceptos (Valero Sancho:

1. Comunicación intercultural,

2. Publicidad social

3. Democracia intercultural

En principio sobre la Comunicación Intercultural se puede decir que es un campo de estudio relaltivamente reciente y por eso todavía se debate su delimitación. En el campo de la comunicación, Gudykunst (1987, p. 848), reúne los aportes más significativos de este campo de estudio y formula cuatro áreas de estudio: 
La "comunicación intercultural", protagonizada por actores de diferentes pueblos o contextos socioculturalres disímiles. (Gudykunst y Ting---Tooney, 1988). La "comunicación transcultural", que consiste en comparar la forma en la que miembros de dierentes culturas se comunican en el plano interpersonal. (Brislin, 1986). La "comunicación internacional", relacionada con las políticas mediáticas de las naciones y los medios masivos de comunicación (Hamelink, 1989). Finalmente, la "comunicación de masas comparada", que las diferencias entre la forma de tratar la información sobre un suceso en distintos paísesy los efectos de estos contenidos (Blumler, McLeod y Rosengren, 1992).

En el contexto de este artículo, considero más pertinente diferenciar la comunicación en términos de "intercultural", "interpersonal" y la "comunicación intercultural mediada" que correspondería, por ejemplo, a los mass media. Para dejarlo más claro, se entiende por "comunicación mediada" como aquella en la que hay una producción mediatizada del discurso" (Alsina, 2006)

En años recientes, la Publicidad Social, se ha vuelto un campo de estudio potenciado por la necesidad de empresas del sector público y privado para generar campañas publicitarias que permitan relacionarse de manera más directa con sus públicos objetivos, esto hace de ella, un área estudio del que bebe diferentes disciplinas. (Toro, 2010).

Todas estas visiones coinciden con el carácter de "desarrollo integral" de la Publicidad social en cuanto está relacionada a "cambios actitudinales desde lo cultural", trascendiendo del concepto de consumidor (sujeto pasivo finalizado a la compra) y entrando a dialogar con el ciudadano (sujeto activo que debe-quiere participar).

Sobre la Democracia intercultural, más allá de un modelo incluyente, donde cada diferencia y minoría está presente y representada a pleno título y con toda dignidad en la sociedad dominante, la sociedad intercultural permitiría una inclusión recíproca de todas las otredades, mayoritarias $y$ minoritarias.

Por medio de un proceso de reconocimiento de las múltiples diferencias que residen en su interior, esta Democracia intercultural tiene la capacidad de mejorarse constantemente gracias a la transformación 


\section{- ¿Existe la Publicidad Intercultural? - Francesca Senesi, David Ricciulli-Duarte}

positiva de los múltiples conflictos que surgen dentro de ella. De hecho, son precisamente estas luchas las que permitirían la expresión de las infinitas posibilidades que ofrecen las perspectivas de otros que la constituyen (Sclavi, 2011).

Por lo tanto, mientras que en una democracia radical,

“(...) uno tiene que reconocer que una comunidad politica completamente inclusiva nunca podrá existir. Siempre habrá un "afuera constitutivo", un exterior a la comunidad que es la condición misma de su existencia. Una vez que hemos admitido que no puede haber un "nosotros" sin un "ellos" y que todas las formas de consenso están basadas por necesidad en actos de exclusión, el problema ya no puede ser la creación de una comunidad completamente inclusiva donde el antagonismo, la división y el conflicto desaparecen. Por lo tanto, tenemos que aceptar la imposibilidad de una realización total de la democracia” (Mouffe, 1993, pág. 9).

En la democracia intercultural, por el contrario, se puede admitir el cumplimiento de la democracia porque el conflicto, lejos de cesar de existir, sería la herramienta básica del desarrollo de la inclusión social mediante la transformación positiva de los diferentes contrastes. Solo así, la emergencia de los intereses particulares y antagónicos permitiría brindar a un bien común la finalidad última de la democracia.

Hablar de "transformación de conflictos" es

"científicamente sólido porque la literatura y la investigación sobre conflictos convergen en dos ideas comunes: el conflicto es normal en las relaciones humanas y el conflicto es un motor para el cambio. Y la transformación es clara en visión porque permite enfocar el horizonte al cual viajamos, puntualmente la construcción de relaciones y comunidades sanas, tanto local como globalmente. Este proceso requiere cambios significativos en nuestros modos actuales de relación".

(Maiese M., Lederach J.P., 2009, pág.2)

Esta metamorfosis política necesitaría, evidentemente, una "conversión cultural” y ¿qué podría producir este poderoso cambio actitudinal mejor que la publicidad intercultural en su significado más profundo e innovador?

\section{Marco teórico}

Para el proceso de definición de la "Publicidad Intercultural", se buscará aclarar si esta es el reflejo de una sociedad intercultural, si contrariamente la genera o, si ocurren ambas cosas. 


\section{La Publicidad según Bauman}

El recorrido teórico para definir a la Publicidad Intercultural debe iniciar ocupándos de la Publicidad en primer lugar, para desarrollar lo entendido como la interculturalidad y finalmente describir la relación entre los dos conceptos.

La publicidad consiste en persuadir a un consumidor para que elija un determinado producto o servicio. El fenómeno de la publicidad, en un sentido más técnico, es relativamente reciente porque, tal como la conocemos, surge después de la Segunda Guerra Mundial y la naciente Sociedad de Masas. Solo con la existencia de infinitos potenciales consumidores y productos, la publicidad puede llegar a su apogeo.

Es razonable desde este punto de vista pensar la Publicidad como una herramienta aliada de la llamada Sociedad del Consumo. Si "eres, lo que consumes", la publicidad se vuelve casi la única brújula para orientarse en la actual posmodernidad líquida. "Etiquetas, logos y marcas son los términos del lenguaje de reconocimiento." (Bauman, 2009).

La Publicidad es un poderoso constructor de identidades y sociedades, pero no podemos olvidar que es también un producto de cada era específica de la historia, en tanto que evoluciona con ellas. Y es propiamente la era de la globalización la que nos hace hablar de "Publicidad Intercultural".

\section{Post-modernidad y otredad}

Al ubicarse en el contexto contemporáneo, es preciso definir las características de lo que generalmente se define como "Post-Modernidad".

En un sentido amplio se entiende como un escenario "líquido" en el que coexisten conceptos, que desde el punto de vista "moderno" se considerban contradictorios. Al diluirse la visión occidental hegemónica de la sociedad, se empieza a aceptar una nueva sensibilidad que empieza a tener en cuenta diferentes perspectivas. Es clara, por ejemplo, la emergencia de ideas y conceptos que desafían las clasificaciones unitarias o binarias, pero más allá de su aparición, lo que hace de estas perspectivas importantes es su demanda por la legitiminsad y participación. Marianella Sclavi puede afirmar "Creo que podemos apreciar más la complejidad de los cambios en el acto, si subrayamos...la solicitudpretensión de "co-protagonismo universal" (Sclavi, 2011) 
Esta demanda de legitimación, reconocimiento y protagonismo se refleja en la Interculturalidad, que no se limita a una defensa de las distintas otredades, porque su esencia se fundamenta en el amor a ellas. Este cambio es tan profundo que podemos hablar de un nuevo paradigma epistemológico y axiológico, que considera la diferencia comoel eje fundamental de interpretación y valoración de la realidad.

\section{Interculturalidad como nuevo paradigma epistemológico y axiológico}

El poder de la interculturalidad está en su capacidad para cuestionar algunas de las realidades sociales y culturales aparentemente consolidadas. Así mismo, el fenómeno de la interculturalidad es sujeto a múltiples cuestionamientos. Concebida desde la perspectiva de las identidades de Castells (1998), el fenómeno de la interculturalidad pasa a ser un conjunto de atributos subjetivos construido desde una cultura dominante, para referirse a una no dominante.

En muchos sentidos, ocuparse de la Interculturalidad así como de la Paz, no es una opción neutral, porque pone como base del saber el interés para una convivencia positiva y enriquecedora entre distintas culturas. Es, entoncs, una aspiración ética, y por eso también política, que supera una motivación puramente teórica, y por eso verazontológica."El problema de la paz no es un problema teórico. Más bien es la razón práctico-moral la que expresa en nosotros su veto irrevocable: no debe haber guerra" (Martínez-Guzmán, 2005, p. 89).

Esta línea de pensamiento pertenece a un origen muy antiguo que, surgiendo de Platón con su prioridad del Bien por respecto al Verdadero, mediante Kant y su imperativo ético, llega hasta la "democracia deliberativa” de Habermas (1994). Sobre el concepto de una política deliberativa y la defensa del bien común de Bauman(2007).

Una etapa relevante en este camino es la filosofía de Emmanuel Lévinas (1977) que en "Totalidad e Infinito" sustenta fuertemente la prioridad de la Ética relativamente a la Ontología, interpretando toda la filosofía Occidental como una totalización englobante del "Otro".

La cultura debe su existencia y su permanencia a la Comunicación. Así podríamos considerar que es en la interacción comunicativa entre las 
personas donde, preferentemente, la cultura se manifiesta. Si aceptamos estas ideas debemos señalar qué otras ideas de cultura quedan descartadas y qué consecuencias tiene la orientación escogida. Si partimos de esta postura interaccionista de la cultura, podemos descartar una concepción esencialista de la cultura. Es decir, la cultura no es algo que está más allá de los seres humanos, no es algo inamovible y ahistórico; forma parte de la esencia permanente de una comunidad de vida. La cultura se construye por la interacción de los seres humanos pero al mismo tiempo jamás está definitivamente construida porque, continuamente por la propia interacción de los seres humanos, está en proceso de construcción. (Alsina, 1999, p. 2). La "Interculturalidad" sugeriría entonces una relación entre diferentes culturas.

Alsina (1999), expone cuatro criterios que tradicionalmente se han usado para determinar la diferencia entre una cultura y otra: la lengua, la religión, el género y la edad, pero enfatiza en la naturaleza reductiva de esta clasificación, pues recae en una visión estática y esencialista de la cultura. Los criterios que tradicionalmente se han utilizado para hablar de estas diferencias se desdibujan en la contemporaneidad pues la sociedad actual se caracteriza por su pluralismo cultural y por ello es casi imposible definir las fronteras entre una cultura y otra (Alsina, 1999, p. 2).

\section{Génesis del concepto de interculturalidad}

Para comprender la naturaleza de esta relación entre culturas que implica la Interculturalidad, debemos analizar su genealogía histórica, o sea analizar cuándo y porque nace este concepto.

Estas consideraciones son producto de una reflexión derivada de varios años de trabajo de la autora principal, como "Formadora Intercultural", puede entenderse como una especie de investiga-acción que refleja, como tal, un punto de vista personal y vivencial, si bien se suporte en estudios, profundizaciones y debates conducidos por equipos interdisciplinarios pertenecientes a Instituciones Públicas y Corporaciones Internacionales en el área que se suele comúnmente llamar "Educación para el Desarrollo".

En Europa y sobre todo en Italia, donde se enfocó principalmente la mirada de la autpra, el boom 


\section{- ¿Existe la Publicidad Intercultural? - Francesca Senesi, David Ricciulli-Duarte}

económico seguido a la Segunda Guerra Mundial, la "Descolonización” de África y Asia con su conflictos armados internos y los Regímenes Dictatoriales del Latino América provocaron un vasto fenómeno migratorio que de las ex colonias se reversaba en las Madre-patrias o países de origen (como para los Argentinos con Italia).

Inicialmente la inmigración se caracterizó por ser de orden político (o sea constituida por gente exiliada), posteriormente asumió una naturaleza económica: de los rincones pobres del planeta, que generalmente resultaban ex colonias, se movían personas en búsqueda de oportunidades laborales en las regiones ricas. Este movimiento migratorio se volvió masivo por la llamada Globalización. El continente europeo, por primera vez, después de muchos siglos de las "Invasiones Barbáricas" y de la "Expansión Árabe", se encuentra al "Otro" en su casa y debe relacionarse con él.

Anteriormente el Colonialismo y el Imperialismo, por ejemplo la Conquista de América, habían relacionado el Viejo Continente con diferentes culturas, pero todo eso había pasado fuera del suelo europeo. Ahora el "Extranjero" vive en las ciudades y pueblos de Europa, reclamando nuevos derechos políticos, sociales, económicos, educativos y culturales y se hace ineludible una reacción.

Como explica muy bien Martín-Barbero (2001):

"Pasan al primer plano, derechos de ciudadanía vinculados a las diversas comunidades culturales que conforman una nación desde la doble perspectiva, tanto de su construcción jurídica como ética, esto es desde el nuevo valor de la diferencia que articula la universalidad humana de los derechos a la particularidad de los muy diversos modos de su percepción y de expresió" (p. 18).

\section{Varios modelos de relación con el otro}

Las transformaciones sociales del siglo XXI se pueden resumir en dos paradigmas que organizan el conocimiento de las relaciones interculturales: el del "contacto" y el de la "dominación". Tanto las teorías del contacto cultural como en las centradas en la dominación se concibe, casi siempre, a las sociedades como si fuesen dueñas de una cultura homogénea, una cultura nacional o étnica, que se enfrenta a otras igualmente compactas. 
Para reconceptualizar la naturaleza de las relaciones interculturales entre los africanos, asiáticos y latinoamericanos que viven en Europa y Estados Unidos?, es preciso acudir a la obra de Martín-Barbero (2008):

"la cantidad de homenajes a la diversidad cultural es inversamente proporcional al proceso de reconocimiento real de la heterogeneidad. $Y$ hay procesos a través de los cuales podríamos ver ejemplificado todo esto: de un lado está la manera en la que, no sólo los gobiernos, sino buena parte de la sociedades europeas, están reaccionando a una diversidad cultural que no es la diversidad lejana que habita África o América Latina, sino que habita España, Francia, Alemania o Inglaterra, que habita en la vida cotidiana de la gente" (Martín-Barbero, 2008, p. 14).

Destacamos, entonces, algunas maneras de reaccionar a la diversidad:

1. Posición rígida: "o los inmigrados se asimilan e integran a mi cultura, o se van", un integralismo mono-cultural que esconde un etnocentrismo racista (la idea de una superioridad blanca u occidental).

2. Posición medio-abierta: "respeto tu cultura, tus diferencias y tus idiosincrasias, pero existes solo en un espacio exclusivo para ti, donde no entras en relación conmigo". Estamos hablando de un multiculturalismo que, con una apariencia de tolerancia, respeto y abertura, esconde un etnocentrismo profundo. Etnocentrismo típico de muchas culturas, que se ven a sí mismas como el centro del universo y definen las otras en términos negativos (no son como yo). En el caso específico de las migraciones, obviamente no estamos de frente a una relación simétrica porqué los inmigrantes, en cuanto minoría, no tienen el mismo poder de los autóctonos.

3. Posiciones abiertas:

a. Transculturalidad, que se centra en los elementos culturales que transitan de sociedad en sociedad (La recurrrencia de mitos o cuentos de hadas en diferentes cultuas) y rasgos culturales que transitan de un lugar a otro y se modifican progresivamente (Por ejemplo, la llegada del Flamenco a España desde la India por cuenta de la comunidad gitana). También se considera la capacidad de moverse en varias culturas (Por ejemplo, un ciudadano con doble o triple nacionalidad), o lo que pertenece a todos los seres humanos independientemente de su cultura, como los Derechos Humanos. Como lo define Verónica Hidalgo (2005) 
"Finalmente, indicar que también se empieza a hablar de "transculturalidad" como un proceso de acercamiento entre las culturas diferentes, que busca establecer vínculos más arriba y más allá de la cultura misma en cuestión (...) manifestada en el acuerdo, respeto y promoción de unos valores universales por encima de peculiaridades de raza, etnias $y$ hasta religiosas, caminando decididamente hacia la fraternidad universal" (p. 79).

b. Interculturalidad: Un proceso que busca un intercambio fructífero y pacífico entre las culturas mediante una relación simétrica y complementaria. "Cambio yo y cambia el otro y ambos salimos beneficiados".

De lo afirmado, se podría concluir que la Interculturalidad y la Transculturalidad representan las dos caras de una misma moneda, o sea que reflejan el mismo fenómeno mirándolo de diferentes perspectivas. La primera de hecho se enfoca en lo que es diferente (padres) y la segunda en lo que es común (hijos) a las varias culturas que empiezan a dialogar.

\section{La interculturalidad como amor a la diferencia}

En este sentido de apertura a la diferencia es el "Discurso de Diotíma" en el Banquete platónico. Ella, mujer y extranjera, es la única que puede hablar sabiamente sobre el misterio del Amor, tanto que el mismo Sócrates la reconoce como maestra (Muraro, 2003). El Amor es hijo de papá Poros (Oportunidad-Abundancia), y la mamá Penia (Pobreza), como nos cuenta Platón en el Banquete "Y ahora, como hijo de Poros y de Penia" y de esta manera da cuenta de que la unión de aquello que es diferente y opuesto puede generar amor. La Interculturalidad es posible entenderla como "amor a la diferencia" y la diferencia como la procreadora del amor, en un círculo virtuoso que se retroalimenta.

Además, podemos observar cómo solo después de haberse "quitado la ropa", o al haber abandonado todo los preconceptos y prejudicios, se puede entrar en intimidad con el otro. Ocurre, entonces, producir un "Desplazamiento" que permite ponerse empáticamente en los zapatos del otro, superando el etnocentrismo y sucesivamente adquirir más sabiduría y "completud".

Uno de los filósofos que mejor ha descrito la aventura de la Interculturalidad es Lévinas (1977). Compara dos figuras míticas de Occidente para explicarnos el verdadero encuentro con el Otro. Tanto el 
viaje de Ulises como lo de Abraham representan el encuentro con la Alteridad, pero en distintas formas. En efecto Ulises sale de Ítaca para volver, después de muchas peripecias, a la misma isla natal. Por el contrario, Abraham sale de su Ur para una tierra desconocida, solo confiando en una promesa del Otro Infinito que lo llama.

Así, cuando empezamos el viaje para encontrar un ser diferente a nosotros, siempre sabemos de dónde salimos, pero nunca conocemos adonde llegaremos. En efecto, quien se mueve sin ser abierto, está destinado a nunca encontrar su interlocutor, solo se reflejará en un estanco como Narciso, arriesgando además su vida en un suicidio involuntario. Lo que significaría la extinción de una civilización sin el aporte de las otras.

Como bien afirma Panikkar (2006):

"Todas las culturas son el resultado de una continua fecundación mutua. Las culturas, como la realidad, no son estáticas, sino que están en proceso de transformación continua. El diálogo entre culturas, así como la labor filosófica de intentar ser conscientes del propio mito, de cuestionarlo $y$ de transformar$l o$, de encontrar equivalencias entre discursos culturales diferentes, constituye el proceso mediante el cual cada persona humana y cada cultura cooperan al destino de la humanidad y del universo, que, en buena parte, está en nuestras manos. Esta es la dignidad y la responsabilidad humanas.

\section{Interculturalidad como sacralidad del Otro}

Este cambio paradigmático en el que el Otro pasa a ser valioso, está reflejado, en una "Teología de la Diferencia", es decir, abarca la mismísima idea que tenemos de Dios. En efecto, en esta perspectiva, Dios se nos revela no tanto como Uno eternamente autocomplaciente, cuanto como Infinitamente Otro, Infinita Otredad.

La relación con lo infinito no puede, ciertamente, expresarse en términos de experiencia, porque lo infinito desborda el pensamiento. En este desbordamiento se produce de tal suerte que será necesario aludir a la relación con lo infinito de un modo distinto que en los términos de la experiencia objetiva. Pero si experiencia significa precisamente relación con lo absolutamente otro -es decir, con lo que siempre desborda al pensamiento- la relación con lo infinito lleva a cabo la 


\section{- ¿Existe la Publicidad Intercultural? - Francesca Senesi, David Ricciulli-Duarte}

experiencia por excelencia. (Lévinas, 1977, p. 51)

Directa consecuencia de esta “Teología de la Diferencia” es una nueva concepción epistemológica: la Verdad es infinitamente otra y se construye con el Otro. Pero, si la Verdad es inalcanzable ¿dónde encontrar el fundamento de todas las ciencias?

Lévinas contesta atribuyendo el fundamento a la ética: nosotros somos retenes del Otro, que de siempre justifica nuestra existencia como sus responsables (Lévinas,1977).

De acuerdo a estas premisas, el saber tiene una vocación social que, en esta época histórica globalizada y migrante no puede concretarse mejor que como misión intercultural.

\section{La competencia intercultural}

Pero, ¿cómo podemos volvernos interculturales? ¿ O sea la Interculturalidad es una habilidad innata o una competencia adquirida culturalmente?

Un individuo expuesto a un ambiente multicultural puede adquirir diferentes disposiciones: de aceptar la Interculturalidad, la conflictiva (negarla), o la monocultural (rechazarla). De la misma manera, un Estado donde conviven varias culturas puede adoptar posiciones similares generar políticas consecuentes con estas posturas.

Nos atrevemos a decir que la interculturalidad se produce mediante una educación y política interculturales, herramientas básicas de una ciudadanía mundial o "planetaria" (Morin, 1999) o "cosmopolita" (Nos-Aldás, 2010) que logre una convivencia pacífica entre todas las culturas.

Hay quien, como Balboni, considera que la Comunicación intercultural, no se enseña "En efecto no es posible hablar frontalmente sobre la Comunicación intercultural, no es posible "enseñarla", pero sí se aprende "Parafraseando el discurso de Wilhem Von Humbldt acerca de la enseñanza de los idiomas extranjeros: no se puede enseñar la comunicación intercultural, se puede por lo máximo crear las condiciones para que alíen la aprenda..."(Balboni, 1999) ${ }^{1}$.

Sobre los mecanismos de aprendizaje de la interculturalidad, el consesnso es que la práctica es el método más efectivo "Se piensa al mismo tiempo que -la competencia

$1 \quad$ Traducción del autor 
comunicativa intercultural- pueda ser "aprendida", o más allá de la obvia simplificación, que se puedan crear, también en el aula, unas condiciones que ayuden a establecer relaciones positivas con gente de otras culturas" (Zorzi,1996).

La interculturalidad tiene dos aproximaciones, una teórica y otra práctica. Se necesita, por lo tanto, adoptar metodologías coherentes porque no existe Interculturalidad sin una práctica intercultural. Entre estas prácticas educativas que, obviamente, se transforman en competencias interculturales, se deben enumerar:

La escucha activa, como la definiría Marianella Sclavi "Si quieres comprender lo que otro está diciendo, tienes que asumir que tiene razón, y preguntarle para que te ayude a ver las cosas y los acontecimientos desde su perspectiva". (Marianella Sclavi, 2011, p. 110), que me permite "salir de sí mismo" y "ponerse en los zapatos del otro".

La trasformación positiva de los conflictos, que ayuda a trascender por encima de ellos sin eliminarlos porque estos son connaturales a las diferencias y no existen diferencias sin conflictos. Como sugiere Calderón-Concha "Una de las lecciones que Galtung afirma reiteradamente haber aprendido en sus ya 50anos de trabajo como investigador sobre la paz es que las teorías de los conflictos son para la eternidad" (2009, p. 67).

La creatividad, o sea la capacidad de generar una nueva mirada y acción sobre la realidad en consecuencia de la interacción con el otro, dado que "la primera tarea de la transformación de conflictos no está en hallar soluciones rápidas para los problemas más urgentes, sino generar plataformas creativas que puedan al mismo tiempo detectar los temas más visibles y cambiar las estructuras sociales y los patrones de relación subyacentes" (Lederach \& Maiese, 2009, p. 5)

La cooperación, que nos permite percibir el otro como aliado y salir todos beneficiados del conflicto porque "la mayoría de las negociaciones no son del tipo que los matemáticos llaman juegos de suma 0 , aquellos en los cuales lo que gana uno lo pierde el otro. Al revés las negociaciones son situaciones donde generalmente es posible encontrar soluciones en las cuales ambos ganan más. (Ogliastri, 1997, p. 13). 
La interculturalidad, en efecto, es conectiva y no contrastativa”, es agregativa más que exclusiva. Como profundiza Sclavi "La responsabilidad compartida en conducir el proceso, crea un sentido de co-protagonismo, de común participación en las decisiones y valoraciones y la solución no es ni "o/o" ni " $y / y$ ", sino del tipo "nily" o bien alguna combinación de todas éstas" (Sclavi, 2011, pág. 116).

A nivel propiamente político, la base de la interculturalidad tiene como premisa la igualdad de todos los ser humanos, tanto que Bauman (Bauman, 2007) subraya que la actual defensa de la diversidad tiene sentido sólo en la búsqueda de un bien común para toda la humanidad: la diversidad que se opone a este bien, no debe ser apoyada, al contrario, debe tener una firme oposición.

En efecto, un excesivo enfoque diferencial acabaría probablemente en una discriminación: subrayar la diferencia, provocaría en quien posee algún género de diversidad un sentido de exclusión respecto a todos los otros "normales".

De otro lado, eliminar la diferencia conduciría al resultado opuesto, pero igualmente temible. Por eso el filósofo Lévinas, diferentemente de Buber (1995) (que coloca simétricamente el Yo y el Tu), construye una jerarquía inversa a la ordinaria, poniendo el Otro, como infinito e inalcanzable, siempre asimétricamente más en alto y allá del "Yo". Solo así piensa garantizar la sobrevivencia de la Diversidad fruente a la voracidad de la Identidad.

En efecto, muchas civilizaciones antiguas derivan su fundación de un extranjero (ej. Enea) que, casándose con la princesa autóctona, origina una estirpe de héroes y semidioses como los futuros Romanos.

Ciertamente ahora las cosas son muy distintas de la época de Enea y Ulises: las mujeres, cansadas de esperar en la casa, como Penélope, el regreso de sus esposos, se mueven solas por todo el mundo. Desafortunadamente, en la actualidad, la migración femenina, responde a motivaciones más relacionadaS con las exigencias del mercado global, que con la voluntad de las mujeres.

Concluyendo, podemos afirmar que la Interculturalidad es la necesidad y el reto más desafiante para la Educación y la Política: la posibilidad de lograr el bien común, una convivencia pacífica, una sociedad mutuamente y totalmente incluyente. 


\section{Discusión}

\section{La publicidad intercultural como derivada de la Publicidad Social}

¿Qué sentido tiene, entonces, hablar de Publicidad Intercultural?

Como se afirmó inicialmente, la publicidad intercultural puede entonces entenderse de dos maneras: 1) como publicidad que refleja una sociedad intercultural, lo que es todavía lejos de haberse y 2) como una publicidad que aspira a desarrollar y construir una sociedad intercultural.

Existe una Publicidad Social que tiene como objetivo un cambio mental, actitudinal y comportamental en los interlocutores, concebidos más como ciudadanos que como consumidores, el dilema que menciona García Canclini en su "Consumidores y Ciudadanos. Conflictos multiculturales de la globalización" (1995): "La publicidad social aparece en 1942 con la creación de una nueva categoría publicitaria por parte del Ad Council: la publicidad de servicio público" (Feliu-Garcia, 2004, pág. 3).Este mismo nicho es desde donde reside un espacio para la Publicidad Intercultural.

En efecto si, come dice Codeluppi (2007) "La publicidad desempeña una gran importancia en el plano social. Incluso, podría decirse que es uno de los actores más potentes que actúan en el proceso de la producción de la cultura de la sociedad contemporánea" (p. 150), es imposible negar su enorme responsabilidad social. La publicidad, en realidad, no se limita a involucrar el lado intelectual, es capaz de mover el corazón (conmover) y determinar a la acción.

En específico la publicidad social logra cumplir con lo que requiere el perfecto orador para Cicerón "El mejor orador es el que enseña, deleita y conmueve a los oyentes" (Cicerón, pág. 277).

Esta responsabilidad significa, al mismo tiempo, una inmensa oportunidad de cambio en el espacio público.

\section{Características de la \\ Publicidad Interculfural}

Entonces, considerando las enormes posibilidades que se abren frente a la publicidad tradicional por medio de la publicidad social, ¿cómo podemos caracterizar una Publicidad Intercultural?

Enfocándonos en la segunda acepción, que concibe la publicidad como promotora de una 


\section{- ¿Existe la Publicidad Intercultural? - Francesca Senesi, David Ricciulli-Duarte}

cultura ciudadana distinta, podemos afirmar que ésta promueve la interculturalidad cuando favorece el respecto y el amor por la diferencia, transformándose necesariamente en un elemento incluyente.

Consecuentemente en las pautas deberán emerger las diferencias en una manera digna y enriquecedora, promocionando una dimensión dialógica e interactiva entre los diferentes actores, donde el "Inter" juegue un papel fundamental.

Es muy importante, además, que el "Otro" no se represente a partir de una mirada particular, que podría generar una visión etnocéntrica y racista. Se propone favorecer una auto-representación de cada alteridad, dando paso un intercambio de miradas recíprocas que logren deconstruir los preconceptos y prejuicios iniciales para crear nuevos paradigmas.

Entonces, para conseguir la interculturalidad de la publicidad, hay de involucrar al "Otro" en todo el proceso: desde la creación de la pauta hasta su realización final.

Teniendo en cuenta la complejidad de lograr una coparticipación de la otredad, es muy difícil encontrar una publicidad intercultural en la realidad porque, cuando quiero vender algo, la diferencias culturales tendrían que desaparecer fruente a los beneficios universales que brindan el producto o servicio promocionado (Montez-Fenández, 2006).

El ejemplo más representativo es la publicidad de Benetton, que en apariencia realiza perfectamente el ideal de la interculturalidad, porque evidencia y celebra la diversidad. A bien observar, todavía, la diferencia es exaltada para negarla inmediatamente después en la invitación implícita a "ponerse la misma ropa".

La misma estrategia se encuentra en las campañas publicitarias de la multinacional Coca Cola: la enorme presencia de personas de varias etnias en sus spots, parece más bien una confirmación del "valor universal" de la gaseosa que una promoción equitativa de la diversidad cultural.

El caso McDonald's es muy interesante, porque no se limita a publicitar los mismos productos, llegando hasta la adaptación de su oferta culinaria a los gustos de los consumidores locales (ej. Almuerzo Colombiano"), pero ¿es esa una real celebración de la diferencia, un poner en discusión los propis valores institucionales (su identidad) en diálogo con las otras culturas, o es 
simplemente una reafirmación del modelo capitalista, hijo de la tradición occidental?

Es verdad que algunas marcas intentan adaptar sus productos a distintos segmentos culturales (Cepa-Giralt, 2009), pero eso no es propiamente hacer interculturalidad.

El enfoque intercultural no busca exclusivamente adaptarse a las diferencias, busca ir más allá, promoviendo la interacción de ellas para conseguir algo novedoso $\mathrm{y}$ compartido, sea eso una política o un producto comercial.

Lo que, en nuestros días, me parece se acerque más a la Publicidad Intercultural son ciertas campañas organizadas de Organizaciones No Gubernamentales (ONGs) que denuncian comportamientos lesivos contra los derechos humanos en general (por ejemplo, el derecho al agua potable) o contra aquellos específicos de algunas poblaciones vulnerables y a riesgo de exclusión (etnias minoritarias, mujeres, niños, etc.).

Pero esta crítica a modelos intolerantes e irrespetuosos de la diversidad, incluida la del medioambiente, constituye solamente la primera etapa de la interculturalidad, o sea la "pars destruens". En efecto, es necesario despojarse de una mirada etnocéntrica para poder entender la diferencia, se debe producir aquel vacío caótico-creativo que permita escuchar activamente al "Otro" (Sclavi, 2011). Solo_esta conciencia crítica permitirá una comunicación genuina con el interlocutor y así desarrollar juntos infinitos mundos posibles ("pars construens").

Por esa posibilidad de incluir la otredad, la publicidad intercultural, como toda la publicidad social, es un antídoto a la violencia y desarrolladora de lo que Herranz De La Casa (2010) define como "Corresponsabilidad Social Ciudadana" (CSC) que "implica a cada uno de los ciudadanos (incluyendo las empresas- lo añado yo) en la búsqueda de un mundo mejor" (p. 9).

\section{Conclusiones}

Si queremos desarrollar un sentido de "Corresponsabilidad Social Ciudadana" que abarque una dimensión mundial, la única que nos brinda la Post-Modernidad con su Aldea Global, tenemos la responsabilidad de educarnos en la interculturalidad. En este caso, la Publicidad Intercultural se ha venido mostrando como una herramienta poderosa, evidenciando 


\section{- ¿Existe la Publicidad Intercultural? - Francesca Senesi, David Ricciulli-Duarte}

la importancia del papel desempeñado por los publicistas.

Lo importante de la función educativa de la Publicidad Social (y de la Publicidad intercultural como parte de ella) es su capacidad de modificar actitudes y comportamientos enraizados en la sociedad.

Esta característica será primordial en el desarrollo de vínculos entre los agentes de cambio y los adoptantes objetivos, pues al momento de generar acciones de comunicación con fines educativos se afirma un vínculo más duradero y fuerte entre ambas partes. Aunque parezca obvio, es necesario recalcar que la función informativa, pero sobre todo la función educativa de la Publicidad Social, son especialmente importantes en países en desarrollo, donde los niveles de educación son más bajos y se hace necesario acudir a la publicidad para llegar a un mayor número de personas (Toro, 2010, pp. 173-pp. 174). De otro lado, sin una competencia intercultural, se podrán únicamente reproducir los mismos modelos, insuficientes e ineficaces para una realidad extremadamente compleja y multicultural como la actual.

Como afirma Martín-Barbero (2004):
"Todo lo anterior sugiere la necesidad de introducir en el debate una dislocación impensable para los modernos e inaceptable incluso para los más radicales posmodernos: pensar pluralmente la modernidad. Pues la crisis de la razón y del sujeto, el fin de la metafísica y la deconstrucción del logocentrismo siguen teniendo como horizonte la modernidad una, que comparten defensores e impugnadores" (p. 118).

Las diferencias que coexisten en la sociedad se condenarían a la autoextinción si se aíslan unas de otras. Solo el diálogo con la diversidades permitiría genuinamente adquirir la capacidad de solucionar los innumerables problemas de la contemporánea Segunda Modernidad (Sclavi, 2011).

$\mathrm{Si}$ "la globalización exaspera y alucina a las identidades básicas, a las identidades que echan sus raíces en los tiempos largos" (Martín-Barbero, 2001, p. 15), una sociedad intercultural, considera las culturas como abiertas y osmóticas, recíprocamente fecundantes y fluidas, no como fortalezas cerradas e inaccesibles.

A tal sociedad corresponde una identidad nómada y migrante, que acepta ser multíple y mutante, no fija y rígida una vez y para siempre 
(Maalouf, 2012). Una identidad, en suma, que reconozca y acoja adentro sí misma el extraño como parte integrante y primordial de su esencia.

En estas condiciones tiene sentido transformar las tres virtudes teologales en tres virtudes interculturales:

La Fe en la confianza que el otro ser humano puede ser mi aliado y no enemigo

La Esperanza en la certeza que pueda existir un mundo donde las diferencias convivan en paz

La Caridad en justicia y solidaridad para las poblaciones más vulnerables y excluidas. El intento de transformar las virtudes teologales en cardinales-laicas, depende de la necesidad (bien aclarada en $\mathrm{H}$. Kung, también si en forma distinta) de encontrar una ética universal que promueva el respecto y el amor para la alteridad y sea compartibles por cada ser humano, a pesar de su religión, ideología cultura, credo.

\section{Como propone Küng (1999)}

"Este consenso social, que un sistema democrático no debe imponer, sino presuponer, no consiste en un sistema ético común. Consiste en un fondo común que incluye valores y normas, derechos $y$ deberes elementales, una actitud ética común (ethic), es decir, un ethos de la humanidad. Una ética mundial (global ethic) que no es una nueva ideología o "superestructura», sino que enlaza entre sí los recursos religioso-fílosóficos comunes ya existentes de la humanidad, sin imponerlos legalmente desde fuera, sino interiorizándolos de manera consciente". (p. 5).

De todo cuanto dicho anteriormente, se entiende que la Interculturalidad es primariamente una actitud que involucra cada dimensión humana (física, mental, emocional, spiritual) y que repercute también en sus representaciones colectivas como la Política y la Educación.

Un caso ejemplar de lo fundamental que es la interculturalidad lo constituye Colombia: para lograr una paz duradera el País debe reconciliarse con sus numerosas raíces (indígenas, afros, gitanas, árabes, etc.), sin excepción alguna. Cuando estas multíplices tradiciones no son escuchadas y reconocidas, se determina una desconfianza en el poder de la palabra y una fe en la fuerza de las armas, únicas capaces de reclamar una inclusión social.

Es importante sostener que el nuevo y más urgente desafío de la Post-Modernidad es la Interculturalidad y, con esa, la Publicidad Intercultural, pues no puede negarse que, dada la globalización y 
el papel que en la sociedad de consumo juega la Publicidad, ésta desempeña funciones relacionadas con la construcción de una sociedad intercultural. Como herramienta fundamental del capitalizmo, la publicidad, a modo de un mensajero ubicuo e infatigable,anuncia y pregona las ventajas del sistema, $y$ es justo mediante este pregón a través del cual se produce la conexión entre pueblos y sociedades distintas (Rey, 2006, p. 194).

En efecto, ¿cómo sería posible conseguir una mejor sociedad, donde cada uno se sienta perteneciente al común género humano, si no se construye un diálogo entre aquellas múltiples diferencias que constituyen la realidad contemporánea y que demandan fuertemente una legitimación colectiva?

Como recuerda Maalouf (2012): "todos deberían poder incluir en los que piensan que es su identidad un componente nuevo, llamado a cobrar cada vez más importancia en el próximo siglo, en el próximo milenio: el sentimiento de pertenecer también a la aventura humana" (p. 96).

De hecho la comunicación intercultural nos impulsa a aprender a convivir con la paradoja de que todos somos iguales y todos somos distintos (Alsina, 1999, p. 6).

\section{Bibliografía}

Álvarez-Ruiz, A., Carcelén-García, S., López-Vázquez, B., Sebastián-Morillas A. \& Villagra-García, N. (2009). Publicidad e inmigración. Cómo los inmigrantes latinos perciben y reaccionan ante la publicidad. Madrid: ACP. Recuperado de https://www.academia.edu/4960250/Publicidad e Inmigracion

Alsina, R. (1999). La comunicación intercultural (Vol. 22). Anthropos Editorial.

Alsina, M. R. (2006). Los estudios de comunicación intercultural. ZER-Revista de Estudios de Comunicación, 1(1).

Balboni, P.E. Apprendere e insegnare la comunicazione interculturale. Recuperado de http:// venus.unive.it/aliasve/index. php?name=EZCMS\&page_id $=381$.

Balboni, P.E. Introduzione alla comunicazione interculturale. Recuperado de http://venus.unive.it/aliasve/index. php?name=EZCMS\&page_id=382. 
Balboni, P.E. Problemi di comunicazione interculturale con allievi stranieri adulti. Recuperado de http://venus.unive.it/aliasve/index. php? name=EZCMS\&page_id=383.

Baños, J. (2006). Teorías de la democracia: debates actuales. Revista de Investigación Social 2(4). Recuperado de http://www.redalyc.org/ pdf/628/62820402.pdf

Bauman, Z. (2007) Vida de Consumo. México D.C.: FCE.

Bauman, Z. (2009). ¿ qué hay de malo en la felicidad?. Claves de Razón Práctica, 189, 12-15.

Bauman, Z. (2007) Voglia di comunitá. Roma : Laterza

Blumler, Jay G.; McLeod, Jack M. y Rosengren, Karl Erik (eds.) (1992): Comparatively Speaking: Communication and Culture Across Space and Time. London: Sage.

Brislin, Richard W. (1986): CrossCultural Encounters. Face-to-Face Interaction. New York: Pergamon Press.

Buber M. (1995), Yo y Tú, traducción de Carlos Díaz, segunda edición, Caparrós editores, Madrid

Canclini, N.G. Comunicación intercultural. Hacia un balance teórico en América Latina. Recuperado de https://telos.fundaciontelefonica. com/telos/anteriores/num_040/opi_ perspectivas1.html

Calderón Concha, P. (2009). Teoría de conflictos de Johan Galtung. Revista de paz y conflictos, (2).

Castells, M. (1998). Espacios públicos en la sociedad informacional. Ciutat real, ciutat ideal. Significat i funció a l'espai urbà modern.

Cepa-Giralt, Y. (2009). Globalización y diferencias culturales en publicidad. CDC Cuadernos de Comunicación,(3), 9-16.

Cicerón, M.T. Del mejor genero de oradores. Recuperado de http://biblio. juridicas.unam.mx/libros/2/778/13. pdf

Codeluppi, V. (2007). El papel social de la publicidad1/The social role of advertising. Pensar la publicidad, 1(1), 149-155.

Cruz-Moya, O \& Ojeda-Álvarez, D. (2003). El componente intercultural en los anuncios publicitarios o cómo vender gazpacho en Finlandia. Recuperado de http://cvc.cervantes. es/ensenanza/biblioteca_ele/asele/ pdf/14/14_0267.pdf 
Derrida, J. (1995). Adiós a Emmanuel Lévinas. Derrida en castellano. Recuperado de http://www.jacquesderrida. com.ar/textos/adieu.htm

Derrida, J. (1997) Sobre la hospitalidad. Derrida en castellano. Recuperado de http://www.jacquesderrida. com.ar/textos/hospitalidad.htm

Feliu-Garcia, E. (2004). La publicidad social. Recuperado de http://rua.ua.es/dspace/bitstream/10045/15710/1/Emilio\%20 Feliu\%20-\%20La\%20Publicidad\%20 Social.pdf

Galtung, J. (1998). Tras la violencia, 3R: reconstrucción, reconciliación, resolución. Afrontando los efectos visibles e invisibles de la guerra y la violencia. Bilbao: Gernika Gogoratuz.

Galtung J. (2003) Paz por medios pacíficos. Paz y conflicto, desarrollo y civilización. Bilbao: Gernika Gogoratuz.

García Canclini, N., \& Canclini, N. G. (1995). Consumidores y ciudadanos: conflictos multiculturales de la globalización (No. 316.42). Grijalbo,. Gudykunst, William B. (1987): "Cross-Cultural Comparisons", en pp. 847-889 Berger, Charles R. y Chaffee, Steven H. (eds.): Handbook of
Communication Science. London: Sage.

Gudykunst, William B. y Ting-Toomey, Stella (1988): Culture and Interpersonal Communication. London: Sage.

Guzmán, V. M. (2005). La filosofía de la paz como racionalidad práctica. Investigaciones fenomenológicas, (4), 87-98.

Habermas, J. (1994). Tres modelos de democracia. Sobre el concepto de pol'tica deliberativa. Agora: Cuaderno de Estudios PolíticosVol. 1, no. 1 (1994), p. 41-50.

Habermas, J. (1996). L'inclusione dellaltro. Milano: Feltrinelli

Hamelink, Cees J. (1989): “The Relationship Between Cultural Identity and Modes of Communication", pp. 417-426 en Anderson, James A. (ed.): Communication Yearbook/12. London: Sage.

Herranz De La Casa, J.M. (2010). La comunicación de la responsabilidad social: Una forma de participación ciudadana. Sociedad y Utopía, Revista de Ciencias Sociales n 35 (p 201-218). Recuperado de http://new.lasociedadcivil.org/docs/ 
ciberteca/articulo_responsabilidadsocial_jmherranz.pdf

Hernández, V. H. (2005). Cultura, multiculturalidad, interculturalidad y transculturalidad: Evolución de un término. IN MEMORIAM.

Kant, I. (2003) Crítica de la Razón Práctica. Buenos Aires: Editorial La Página S.A.

Kitchenham, B. (2004). Procedures for performing systematic reviews. Keele, UK, Keele University, 33(TR/SE- 0401), 28. doi:http://doi. org/10.1.1.122.3308

Küng, H., \& Marcos, G. C. (1999). Una ética mundial para la economía y la política. Trotta.

Lévinas, E., \& Guillot, D. E. (1977). Totalidad e infinito: ensayo sobre la exterioridad (No. 130.3). Sígueme.

Lederach, J. P., \& Maiese, M. (2009). Conflict Transformation: A circular journey with a purpose. New Routes, 14(2), 7-10.

Maalouf, A. (2012). Identidades asesinas. Madrid: Alianza editorial.

Martín-Barbero, J. (2008). Diversidad cultural y convergencia digital. IC Revista Científica de Información y Comunicación, 5, 12-25.
Martín-Barbero, J. (2004). Nuestra excéntrica y heterogénea modernidad. Estudios Políticos, (25), 115-134. Martín, J. (2001). Tecnicidades, identidades, alteridades: des-ubicaciones y opacidades de la comunicación en el nuevo siglo, en revista. Diálogos, (64), 9-24.

Martínez-Corcuera, R.(2005). Interculturalidad y Publicidad. Mugak, 30. Recuperado de http://mugak.eu/revista-mugak/no-30/interculturalidad-y-publicidad

Martínez Guzmán, V. (2000). Saber hacer las paces. Epistemologías de los estudios para la paz. Convergencia. Revista de Ciencias Sociales, 7(23).

Martínez Guzmán, V. (2005). La filosofía de la paz como racionalidad práctica. Investigaciones fenomenológicas, (4), 87-98.

Montez-Fenández, A. (2006). Globalización y publicidad: El lenguaje universal de los perfumes. Universidad de Alicante, España. Recuperado de http://hdl.handle.net/10045/2855

Morin, E. (1999). Los siete saberes necesarios para la educación del futuro. Unesco.

Mouffe, C., \& Moreno, H. (1993). Feminismo, ciudadanía y política 


\section{- ¿Existe la Publicidad Intercultural? - Francesca Senesi, David Ricciulli-Duarte}

democrática radical. Debate feminista, 7, 3-22.

Muraro, L. (2003). Diotima: Il pensiero della differenza sessuale. Milano: La Tartaruga

Nós-Aldás, E. (2010). Comunicación, cultura y educación para la solidaridad y el desarrollo. Un análisis desde el discurso. TERESA BURGUI \& JAVIER ERRO (coords.), Comunicando para la solidaridad y la cooperación. Cómo salir de la encrucijada. Pamplona: Foro Comunicación, Educación y Ciudadanía, 113-135.

Ogliastri, E. (1997). Una introducción a la negociación internacional. La cultura latinoamericana frente a la angloamericana, japonesa, francesa y del Medio Oriente, Serie Monografías de Administración, (49).

Toro, J. (2010). Comunicación estratégica para campañas de publicidad social. Pensar la Publicidad 4, (2),169190.

Panikkar, R. (2006). Decálogo: cultura e interculturalidad. Cuadernos interculturales, 4(6), 129-130.

Post, N., \& Vangehuchten, L. (2012). Valores interculturales en la comunicación publicitaria internacional: un análisis cualitativo basado en corpus. Pensar la Publicidad, 6(2), 517.

Rey, J. (2006). La publicidad como agente homogeneizador de culturas (ma non troppo). Comunicación, I (4), pp. 193-pp.-206. Recuperado de http://www.revistacomunicacion.org/ pdf/n4/articulos/la_publicidad_como_agente_homogeneizador_de_ culturas.pdf

Sclavi, M (2011). Escucha activa y segunda modernidad. Miscelánea. Revista digital de las ciencias sociales y de la cultura, (1).104-127.

Vergara, E. (2003). Identidades culturales y publicidad. Los usos de la cultura en la creatividad publicitaria chilena. Trípodos 15, pp. 109-pp. 126. Recuperado de http://www.portalcomunicacion.com/dialeg/paper/ pdf/161_vergara.pdf

Vergara, E. (2006). Medios de comunicación y globalización:i destrucción o reconstrucción de identidades culturales?. Anàlisi: quaderns de comunicació i cultura, (33), 95-105.

Zorzi, D. (1996). Dalla competenza comunicativa alla competenza comunicativa interculturale. Babylonia, 2(1996), 46-52. 